\title{
A cultura escolar do campo e o ensino da matemática
}

\section{RESUMO}

Maykon Jhonatan Schrenk maykon schrenk@hotmail.com orcid.org/0000-0001-8327-9147 Paraná (Unioeste), Cascavel, PR, Brasil

Barbara Winiarski Diesel Novaes barbaradiesel@yahoo.com.br

Universidade Tecnológica Federal do Paraná (UTFPR), Toledo, PR, Brasil
Com o objetivo de identificar a presença da cultura escolar do campo no ensino de matemática (anos finais do ensino fundamental) em uma escola situada na zona rural, a presente pesquisa foi fundamentada no aporte teórico-metodológico da História Cultural por meio do conceito de cultura escolar (JULIA, 1990), tendo como fontes: cadernos de matemática dos estudantes do Ensino Fundamental (anos finais); imagens das atividades docentes; Projeto Político Pedagógico (PPP); planejamento do professor de matemática; legislação pertinente; entrevistas com o diretor da escola, com a professora de matemática do Ensino Fundamental e com a pedagoga. O currículo mostrou-se pronunciadamente urbanocêntrico especificamente em relação às aulas de matemática. Apesar de uma forte cultura escolar do campo estar presente na escola investigada, há pouca presença dessa cultura especificamente no ensino da matemática. Como reflexão final, nos perguntamos se, em nossas escolas urbanas, não estamos precisando de elementos culturais próprios das escolas do campo: sentimento de pertencimento, envolvimento da comunidade, formação de lideranças, interdisciplinaridade, trabalho em grupo e valorização das práticas matemáticas locais.

PALAVRAS-CHAVE: Educação do Campo. Educação Matemática. Cultura Escolar. 


\title{
INTRODUÇÃO
}

\begin{abstract}
Em torno das comunidades existentes, historicamente bastante variadas, cristalizaram-se e generalizaram-se atitudes emocionais poderosas. O campo passou a ser associado a uma forma natural de vida - de paz, de inocência e virtudes simples. À cidade associou-se a ideia de centro de realizações - de saber, comunicações, luz. Também constelaram-se poderosas associações negativas: a cidade como lugar de barulho, mundalidade e ambição; o campo lugar de atraso, ignorância e limitação. O contraste entre campo e cidade, enquanto formas de vida fundamentais, remonta à Antiguidade Clássica (WILLIANS, 2011, p. 11).
\end{abstract}

Ao iniciar o texto, refletimos sobre a citação de Raymond Williams do livro "O Campo e a cidade na história e na literatura" que mesmo se referindo a um caso inglês do período da revolução industrial nos ajuda a compreender a vida no campo e alguns entendimentos cristalizados no senso comum pedagógico. Se o campo é entendido como um lugar de atraso, ignorância e limitação, qual seria o entendimento para uma Educação do Campo?

A Educação do Campo ${ }^{1}$ durante muito tempo foi deixada em segundo plano nos discursos sobre educação no Brasil. Um marco na retomada da luta ensino de qualidade, pelo respeito a suas raízes culturais e pelo entendimento de suas singularidades, foi a Primeira Conferência Nacional por uma Educação Básica do Campo promovida em 1998 pelas instituições Movimento dos Trabalhadores Rurais Sem Terra (MST), a Universidade de Brasília (UnB), a Conferência Nacional dos Bispos do Brasil (CNBB), o Fundo das Nações Unidas para a Infância (Unicef) e a Organização das Nações Unidas para a Educação, a Ciência e a Cultura (Unesco). Participaram desse evento educandos e educadores do MST, da agricultura familiar, dos indígenas, dos povos da floresta, dos ribeirinhos, quilombolas, dos sindicatos de trabalhadores rurais (ANHAIA, 2011 apud BRASIL, 2014). A Conferência surgiu como uma alternativa para ampliar a discussão sobre a educação no meio rural brasileiro (BRASIL, 2014, p. 9).

Em relação a como trabalhar a matemática escolar numa escola do campo, concordamos com D'Ambrósio (2005, p. 42) quando afirma que: "reconhecer e respeitar as raízes de um indivíduo não significa ignorar e rejeitar as raízes do outro, mas, num processo de síntese, reforçar suas próprias raízes". Para Ubiratan D’Ambrósio a matemática deve ser entendida nas suas várias dimensões: conceitual, histórica, cognitiva, epistemológica, política, cotidiana, educacional. Sua teoria permite trabalhar a matemática respeitando as especificidades da Educação do Campo e suas implicações didático-pedagógicas.

Conforme crescemos, adquirimos saberes por meio de experiências, ou seja, da nossa vivência na sociedade, na escola, no convívio familiar. Para os alunos que moram no campo, esses tornam-se importantes para seu desenvolvimento, assim como para crianças em outros contextos. Esses saberes não podem ser desprezados, principalmente em uma aula de matemática, embora algumas vezes isso ocorra. Que matemática pode ser considerada legítima? Há uma hierarquia entre a matemática escolar e a matemática do campo? A etnomatemática considera como conhecimento o que rotineiramente não é reconhecido como tal e considera a existência de outras matemáticas (BARBOSA, 2014). 
Etnomatemática, existem outras formas de produzir significados matemáticos, outras formas que são igualmente Etnomatemáticas, pois manifestações simbólicas de grupos culturais (KNIJNIK, 2000).

A Etnomatemática, por meio das pesquisas realizadas e do campo que abriu, deu legitimidade a outros modos de produção de significado para aquilo que se chama matemática (BARBOSA, 2014; KNIJNIK, 2000).

Sem hierarquias, sem diminuir a legitimidade das especificidades de uma matemática do campo, percebemos que considerar essas diferenças pode ser rico para a aprendizagem. Essa bagagem pode contribuir para o desenvolvimento do aluno, o crescimento da sua confiança e motivação na busca do saber na aula de matemática.

Bzuneck (2000, p. 9 apud MORAES, VARELA, 2007, p. 3) afirma que "a motivação, ou o motivo, é aquilo que move uma pessoa ou que a põe em ação ou a faz mudar de curso" e o fato de utilizarmos a vivência do aluno no ensino da matemática tende a motivá-lo, dando chance e segurança para ele mostrar o que já sabe. Segundo Moraes e Varela (2007), "se o conteúdo da aula é interessante para a criança, ela o associa com seus conhecimentos e experiências prévias" ( $p$. 13), e é essa uma das metas de se utilizar a vivência no campo na sala de aula.

Tendo como base a problemática anunciada, os primeiros questionamentos que nos ocorreram: Seria possível a matemática escolar usufruir do campo para auxiliar no aprendizado dos educandos? Como utilizar a matemática no campo, como ensiná-la para alunos que vivem no campo?

A legislação existente sobre a Educação do Campo (BRASIL, 1996, 2002, 2014; PARANÁ, 2006) desmistifica a escola apenas situada no campo. A Educação do Campo, além de se encontrar no campo, segundo Antunes-Rocha e Martins (2009), também significa aprender com a terra, com o campo, os modos genuínos de olhar para a vida do homem em sintonia com a natureza. Além disso, significa conhecer diferentes modos de organização da sociedade e das lutas políticas, e ainda reconhecer o poder dos gestos, das cores, das imagens próprias do campo como saberes legítimos.

É de extrema importância que as atividades de matemática envolvam o conhecimento que o aluno possui, porém, segundo o Plano Nacional de Alfabetização na Idade Certa (PNAIC), "quando apontamos para a necessidade de incorporarmos a cultura dos alunos em nossas práticas pedagógicas, não significa criarmos 'probleminhas' ruralizantes" (BRASIL, 2014, p.24). Esses problemas ruralizantes seriam, por exemplo: realizar uma operação matemática (nesse exemplo a soma) e, para tal, utilizar laranjas e afirmar que esta atividade envolve a Educação do Campo. Mas essa atividade poderia ser feita com carros, casas, celulares, ou algo que se situa em qualquer lugar. Mais do que isso, uma atividade de matemática de uma escola do campo deve preparar os alunos para a vida deles no campo ou fora dele, "pois a escola do campo deve ser considerada como espaço de vida digna, e, sobretudo, de produção de conhecimento para transformação da realidade" (NAHIRNE; STRIEDER, 2017, p. 5).

Conforme exposto anteriormente, a escola do campo possui suas especificidades que nem sempre são compreendidas e respeitadas. Quais as particularidades da escola do campo? Os professores de matemática relacionam a Educação do Campo com os conteúdos escolares? 
Dessa forma, na presente pesquisa objetivou-se identificar indícios da presença do campo (vivência dos estudantes, costumes da comunidade, espaço escolar, organização política, entre outros) na sala de aula, especialmente no ensino da matemática nos anos finais do ensino fundamental. Para alcançar esse objetivo, a investigação se baseou na observação do espaço escolar (pátio, salas, horta, comunidade em geral), em entrevistas semiestruturadas e análise documental. $\mathrm{O}$ trabalho teve uma versão preliminar apresentada no XIV Encontro Paranaense de Educação Matemática - EPREM (SCHRENK; NOVAES, 2017).

\section{HISTÓRIA DA EDUCAÇÃO DO CAMPO}

Somente cerca de meio século após o país ter se transformado em República, é que uma Constituição brasileira, a de 1934, vai tratar da Educação Rural, ainda não chamada de Educação do Campo (BRASIL, 2014, p. 6).

Em 1937, foi criada a Sociedade Brasileira de Educação Rural, com o intuito de expandir o ensino e preservar a cultura do homem no campo, merecendo destaque o elevado número de analfabetos. Após a Segunda Guerra Mundial, foi criada a Comissão Brasileiro-Americana de Educação das Populações Rurais na qual a educação se desenvolvia com o objetivo de proteção e assistência ao camponês, o qual era tratado como carente, subnutrido, pobre e ignorante (PARANÁ, 2006, p. 17).

A partir da segunda metade do século $X X$, começam a surgir movimentos sociais do campo, que passaram a aprender que a luta pela terra era apenas o início da mobilização, porque ela poderia garantir sustento e produção de vida. Porém, outras demandas foram se tornando presentes. Dessa forma a educação e a escolarização dos trabalhadores do campo e seus filhos passaram a integrar a pauta dos movimentos sociais do campo (BRASIL, 2014, p. 8).

Em consequência da nova constituição aprovada em 1988, outras leis foram discutidas e decretadas, como por exemplo, a LDB de 20 de dezembro de 1996. Essas leis levaram ao repensar sobre a educação dos trabalhadores do campo (BRASIL, 2014, p. 7) desta forma a educação começou a se destacar como um direito de todos (PARANÁ, 2006, p. 18).

O artigo 28 da LDB reconhece a especificidade do campo:

\footnotetext{
Art. 28‥ Na oferta de educação básica para a população rural, os sistemas de ensino promoverão as adaptações necessárias à sua adequação às peculiaridades da vida rural e de cada região, especialmente:

I - conteúdos curriculares e metodologias apropriadas às reais necessidades e interesses dos estudantes da zona rural;

II - organização escolar própria, incluindo adequação do calendário escolar às fases do ciclo agrícola e às condições climáticas;

III - adequação à natureza do trabalho na zona rural (BRASIL, 1996, p. 11).
}

Mesmo com esses avanços na legislação educacional, a realidade das escolas para a população rural continuava precária, seja em condições materiais dentro de sala, na escola como um todo, transportes, materiais didáticos (PARANÁ, 2006, p. 18). 
Em 1997, houve um marco na retomada da luta por uma Educação do Campo de qualidade, pelo respeito a suas raízes culturais e pelo entendimento de suas singularidades. Foi realizado o I Encontro de Educadores e Educadoras da Reforma Agrária (I ENERA), organizado pelo Movimento dos Trabalhadores Rurais Sem Terra (MST) com apoio de outras entidades, no qual foi lançado um desafio: pensar a educação pública a partir do mundo do campo (PARANÁ, 2006, p. 19; BRASIL, 2014, p. 8).

Sob influência do contexto de mobilização então vivido, num movimento de base, as escolas do campo espalhadas nos mais diferentes recantos do país estavam realizando práticas que buscavam associar o processo educativo aos interesses dos trabalhadores do campo (BRASIL, 2014, p. 8).

Em agosto de 1997, iniciaram-se as discussões preparatórias para a I Conferência Nacional por uma Educação Básica do Campo, que viria a ser realizado um ano após o ENERA, em julho de 1998 (PARANÁ, 2006, p. 19; BRASIL, 2014, p. 9).

O debate sobre a compreensão de campo trouxe a perspectiva de que campo é mais do que lugar de plantar ou de criar animais para suprir a alimentação da humanidade (BRASIL, 2014, p. 11).

A partir de então, o poder público passou a reconhecer a necessidade de pensar uma legislação específica de educação aos povos do campo. Foram aprovadas em 2002 no Conselho Nacional de Educação, por meio da Câmara de Educação Básica, as Diretrizes Operacionais para a Educação Básica nas Escolas do Campo (PARANÁ, 2006, p. 19; BRASIL, 2014, p. 12). A partir das discussões sobre as Diretrizes Operacionais, foi proposta a utilização do termo Educação do Campo:

\begin{abstract}
A identidade da escola do campo é definida pela sua vinculação às questões inerentes à sua realidade, ancorando-se na temporalidade e saberes próprios dos estudantes, na memória coletiva que sinaliza futuros, na rede de ciência e tecnologia disponível na sociedade e nos movimentos sociais em defesa de projetos que associem as soluções exigidas por essas questões à qualidade social da vida coletiva no país (BRASIL, 2002, p. 1).
\end{abstract}

Ainda no plano das ações em parceria entre os diferentes movimentos e instituições ligadas aos trabalhadores do campo houve, em julho de 2004, a realização da II Conferência Nacional por uma Educação do Campo, contando com mais de mil participantes, representando cerca de 40 entidades (BRASIL, 2014, p. 12).

No estado do Paraná, começou a se pensar na educação para homem do campo a partir de 1990:

Foi criado pelo governo estadual, na gestão 1992-1994, o Programa Especial Escola Gente da Terra, que tinha como propósito 'dar um atendimento específico e diferenciado' aos povos do campo, das áreas indígenas, dos assentamentos e aos assalariados rurais, no nível do Ensino Fundamental e da alfabetização de jovens e adultos (PARANÁ, 2006, p. 20).

Segundo as Diretrizes Curriculares da Educação do Campo (DCEC) (PARANÁ, 2006 , p. 21), a partir de 2000, após vários encontros e reuniões, foi criada a Articulação Paranaense por uma Educação do Campo, que definiu uma pauta de reivindicações para a semana de lutas pela agricultura. Entre as reivindicações, 
estava a criação de um departamento específico para a Educação do Campo, na Secretaria do Estado da Educação, atendida em 2002 com a criação da Coordenação da Educação do Campo na Secretaria do Estado da Educação (SEED).

Desde então, a Educação do Campo passou a ter um espaço de articulação entre o poder público e a sociedade civil organizada. Foram realizados dois seminários de Educação do Campo no Estado, em que estiveram presentes os sujeitos coletivos da Articulação Paranaense por uma Educação do Campo, entre outros (PARANÁ, 2006, p. 22).

Apesar de parecer ter o mesmo significado, o termo "rural" e "campo" possuem concepções diferentes. Segundo as DCEC (PARANÁ, 2006, p. 24), o termo campo é pensado como um lugar de vida, de trabalho, de cultura, da produção de conhecimento na sua relação de existência e sobrevivência, valorizando-os como sujeitos que possuem laços culturais e valores relacionados à vida na terra. 0 termo rural, por sua vez, é pensado a partir de uma lógica economicista, representa uma perspectiva política presente nos documentos oficiais, que historicamente fizeram referência aos povos do campo como pessoas que necessitam de assistência e proteção, na defesa de que o rural é o lugar do atraso.

É importante pensarmos em como deve se dar o ensino na sala de aula para uma escola do campo. As DCEC (PARANÁ, 2006, p. 44) citam que para que efetive a valorização da cultura dos povos do campo na escola, é necessário repensar a organização dos saberes escolares, ou seja, os conteúdos específicos a serem trabalhados.

No caso específico do Paraná, as DCEC (PARANÁ, 2006, p. 44) apresentam duas formas de como pode se dar essa reorganização. Uma delas ocorre nas disciplinas da Base Nacional Comum, onde poderemos observar a articulação dos conteúdos sistematizados com a realidade do campo. Verificar se "os conteúdos culturais dos povos do campo estão presentes nas disciplinas, se os saberes dos povos do campo integram os currículos das disciplinas, são formas de investigar" (PARANÁ, 2006, p. 45) se a Educação do Campo está presente na sala de aula da escola do campo.

Sobre a segunda forma, apresentam que:

[...] ocorre pela criação de disciplinas para compor a parte diversificada da matriz curricular. [...] Porém, é importante salientar que a implementação da Educação do Campo não vai ocorrer apenas com a criação de várias disciplinas na parte diversificada, [...] é fundamental garantir que a realidade do campo, com sua diversidade, esteja presente em toda a organização curricular (PARANÁ, 2006, p. 45).

Na próxima sessão iremos apresentar os aspectos metodológicos da pesquisa, bem como as categorias que emergiram da leitura atenta das fontes de pesquisa.

\section{ASPECTOS METODOLÓGICOS DA PESQUISA}

A pesquisa de caráter qualitativo tem como principal característica buscar dar sentido ou interpretar os fenômenos de acordo com os significados que as pessoas trazem para eles (DENZIN, LINCOLN, 2006).

Para Duarte (2004) o que dá o caráter qualitativo não é necessariamente o recurso de que se faz uso, mas o referencial teórico/metodológico eleito para a 
construção do objeto de pesquisa e para a análise do material coletado no trabalho de campo.

A modalidade de pesquisa utilizada neste trabalho ${ }^{2}$ foi o estudo de caso cujo objeto é uma unidade que se analisa profundamente (TRIVINÕS, 1987). Esse estudo pode ser simples e específico, como o de uma professora competente de uma escola pública, ou complexo e abstrato, como o das classes de alfabetização ou do ensino noturno (LÜDKE; ANDRÉ, 2005).

A pesquisa foi desenvolvida a Colégio Estadual do Campo Teotônio Vilella ${ }^{3}$ situado na zona rural do município de Missal.

Concomitantemente às observações, realizamos entrevistas semiestruturadas com o diretor do colégio (Entrevista A, SCHRENK, 2015), com a pedagoga (Entrevista B, SCHRENK, 2015) e com a professora de matemática do Ensino Fundamental, séries finais (Entrevista C, SCHRENK, 2015). Como critério de inclusão, os entrevistados deveriam estar trabalhando mais de quatro anos na escola. Foram excluídos da entrevista os professores que estiveram afastados por mais de seis meses de suas funções no ano da realização da pesquisa. Elaboramos um roteiro para a entrevista conforme os objetivos da investigação. Segundo Duarte (2004), entrevistas são fundamentais quando se precisa/deseja mapear práticas, crenças, valores e sistemas classificatórios específicos, mais ou menos bem delimitados, em que os conflitos e contradições não estejam claramente explicitados.

Os principais documentos analisados foram as Diretrizes Curriculares da Educação do Campo do Estado do Paraná (2006), os documentos do colégio (PPP, Plano de Trabalho Docente (PTD) da disciplina de Matemática) e materiais dos estudantes (cadernos de matemática do ano anterior ao estudo). Para fazer a análise dos cadernos utilizamos os trabalhos de Gvirtz (2009), que discorrem sobre a relação entre o currículo prescrito e o currículo ensinado por meio da análise dos cadernos dos estudantes. Para Gvirtz (2009, p.25):

\footnotetext{
O caderno é um espaço de interação entre professor e aluno, uma arena na qual se enfrentam cotidianamente os atores do processo de ensinoaprendizagem e onde, portanto, é possível vislumbrar os efeitos desta atividade: a tarefa escolar. A favor da eleição deste objeto se encontra o fato de todos os dias, em quase todas as horas de aula, alunos e professores levam a cabo um minucioso processo de escrituração cujos âmbitos de registro não podem desconsiderar o caderno e a lousa. Assim, o caderno constitui um campo significativo para observar os processos históricos e pedagógicos da denominada "vida cotidiana da escola", nem tanto no que tende as relações de poder interpessoal mas, e sobretudo, no que concerne a produção de saberes.
}

Além disso, segundo Gvirtz e Larrondo (2008, p.39) "tal documento [cadernos escolares] não é considerado em si mesmo, mas tomando como fonte primária neutra para a aproximação de outras questões, permitindo observar que conteúdos se ensinam e como se ensinam" o que justifica o cotejamento com as demais fontes.

Partindo da caracterização de cadernos escolares proposta por Gvirtz (2009), analisamos cadernos dos estudantes regularmente matriculados no ano de $2014^{4}$, sendo um do 6음ono, um do 70 ano, um do 8ㅇ ano e um do 9o ano do Ensino Fundamental. Excluímos os cadernos dos estudantes que reprovaram por nota 
e/ou frequência no ano de 2014. Desta forma, este instrumento é fonte privilegiada para confrontar com as entrevistas e os documentos escolares e compreender se e como ocorre a Educação do Campo na escola investigada.

A análise foi feita de modo a contemplar algumas categorias pré-estabelecidas conforme explicitadas nas DCEC (2006) de tal forma que deem sentido à questão de pesquisa proposta, mas procurando dar "espaço para a emergência do novo" (DUARTE, 2004) com o objetivo de não excluir um dado relevante que não estava previsto no projeto.

Partindo desse entendimento, a seguir serão apresentados aspectos da cultura escolar da escola do campo e as categorias estabelecidas a partir dela para análise dos dados.

\section{CULTURA ESCOLAR DO CAMPO}

De acordo com Julia (2001), a cultura escolar é concebida:

[...] como um conjunto de normas que definem conhecimentos a ensinar e condutas a inculcar, e um conjunto de práticas que permitem a transmissão desses conhecimentos e a incorporação desses comportamentos; normas e práticas coordenadas a finalidades que podem variar segundo as épocas (finalidades religiosas, sociopolíticas ou simplesmente de socialização). Normas e práticas não podem ser analisadas sem se levar em conta o corpo profissional dos agentes que são chamados a obedecer a essas ordens e, portanto, a utilizar dispositivos pedagógicos encarregados de facilitar sua aplicação, a saber, os professores primários e os demais professores (JULIA, 2001, p.10).

Vidal (2005, p.19), porém, compreende a cultura escolar "como constituída pela apropriação criativa de modelos, baseada na relação entre determinantes sociais e históricas e as urgências próprias da organização e do funcionamento escolares".

Desta forma, os determinantes sociais e históricos definem normas, práticas e finalidades que fazem com que exista uma cultura escolar do campo.

Para os estudantes que vivem no campo, é importante que lhes seja permitido apresentar seus conhecimentos prévios ${ }^{5}$ na sala de aula criando "condições para que o estudante desinteressado se torne motivado e proporcionando um ambiente que sustente e otimize a motivação dos aprendizes perante as atividades escolares para que eles as valorizem e desejem nelas se engajar" (CAVENAGHI; BZUNECK, 2009, p. 10) para que ele se sinta à vontade e seguro em uma aula de matemática e possa mostrar para todos o conhecimento que ele traz consigo e como consequência, ter o melhor ensino/aprendizado da matemática possível. Os professores deveriam ter conhecimento sobre a importância de trabalhar a vida do campo e a vida que o estudante presencia dentro da sala de aula.

Valorizar um saber local do campo não significa negligenciar um saber matemático de referência, pois um não exclui o outro. Em entrevista a Barbosa (2014), Gelsa Knijnik fala com maestria sobre os saberes locais e os saberes hegemônicos: 
de vida, então essa é a questão. [...] Quem vai discordar que quaisquer trabalhadores têm o direito a se apropriar dessa linguagem, dessa racionalidade da matemática, que permite que eles passem em provas, que passem em concursos, isso e aquilo, ou o que seja matemática, então isso é óbvio. O problema é que eles [os que estão alinhados com as posições da Pedagogia Crítica dos Conteúdos] não se interessam pela forma de vida dessas pessoas, eles estão dizendo que isso não interessa, não interessa ensinar isso. $\mathrm{O}$ que eu estou dizendo é que estamos de acordo com a primeira parte, mas o preço a ser pago não é esquecer [as práticas matemáticas locais]. Portanto não é uma matemática específica para os do campo, porque, na verdade, eu vou dizer que os da cidade também têm que conhecer essa matemática do campo (BARBOSA, 2014, p. 181)

Após o entendimento do conceito de cultura escolar, dos saberes locais e feita a leitura e releitura dos documentos oficiais da escola, das DCEC (2006) das entrevistas transcritas e dos cadernos dos estudantes, emergiram as categorias de análise sobre a cultura escolar da escola do campo para esta pesquisa, destacadas no Quadro 1.

Quadro 1 - Categorias de análise de dados da cultura escolar da escola do campo

\begin{tabular}{|l|}
\hline \multicolumn{1}{|c|}{ Categorias } \\
\hline - Espaço Escolar; \\
- Organização Política, Movimentos Sociais e Cidadania; \\
- Comunidade; \\
- Concepção dos professores sobre a Educação do Campo. \\
\hline
\end{tabular}

Fonte: autoria própria (2015).

\section{ESPAÇO ESCOLAR}

A escola do campo geralmente possui um espaço escolar que a caracteriza. Segundo as DCEC (2006), os povos do campo querem que a escola seja o local que possibilite a ampliação dos conhecimentos do campo, como a horta escolar, alimentação saudável, remédios caseiros, plantios, para além dos conhecimentos próprios da escola. Segundo o diretor da escola, a horta escolar é um bom exemplo disso, onde os estudantes do colégio ajudam na plantação e cultivo das plantações de diversas hortaliças, além de mandioca e outros alimentos. O cultivo da horta (Figura 1) faz parte do programa Mais Educação ${ }^{6}$, que é um projeto trabalhado dentro do governo estadual a partir de 2014, específico para a questão do campo.

Figura 1 - Horta onde os estudantes auxiliam no cultivo de plantas e verduras

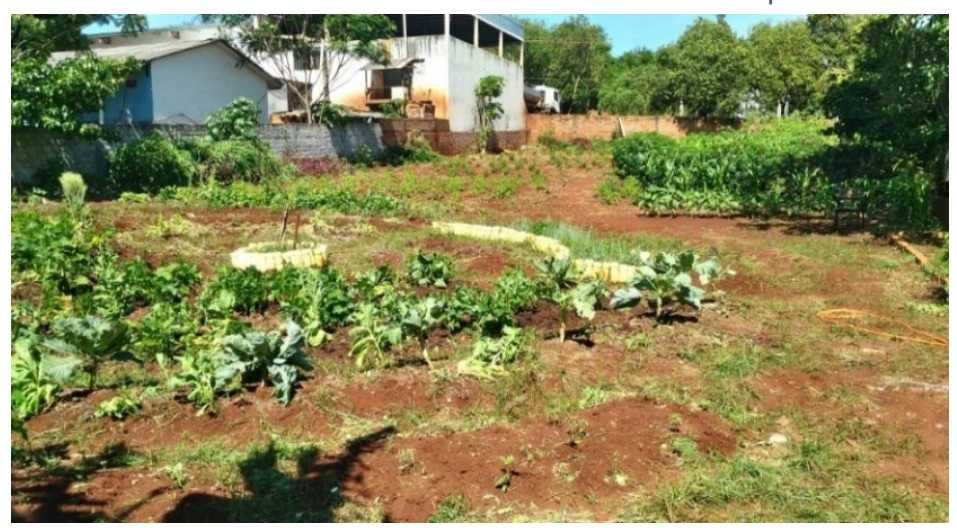

Fonte: autoria própria (2015). 
Outro enfoque do programa é o chamado artesanato regional, coordenado por uma professora do colégio que também é moradora da comunidade. Sobre o artesanato a professora de matemática nos diz que

Tudo aquilo que faz parte da memória, que os nossos avós, nossas famílias faziam de objetos, de utensílios dentro de casa para uso da família vai também para a oficina e para o trabalho de artesanato onde eles produzem os panos de prato, crochês, tricôs, roupas e uma série de outras atividades que são feitas com a visão da Educação do Campo (ENTREVISTA C, SCHRENK, 2015).

Segundo a professora de matemática e a pedagoga, os materiais criados nas aulas de matemática e nas outras disciplinas geralmente são confeccionados em sala e, em seguida, expostos no saguão para as demais turmas.

As DCEC (2006) destacam a importância das atividades que são realizadas fora da sala de aula, citando o campo, os rios, o acampamento, dentre outras atividades, que não podem passar despercebidas e o que pode acontecer por causa do contato diário dos estudantes com esses lugares. Pensando nessas atividades, a escola realiza intercâmbios com outros colégios também na modalidade de Educação do Campo. Segundo os entrevistados, todo ano é comemorado o dia do estudante com outro colégio do campo. No período da manhã é trabalhada a questão cultural, onde os estudantes fazem apresentações, conhecem o colégio, visitam os locais próximos e no período da tarde são realizadas atividades esportivas.

Os trabalhos sobre Educação do Campo são valorizados pelos agentes escolares, sendo uma das estratégias utilizadas a fixação de cartazes pelo colégio.

Segundo as DCEC (2006), o colégio situado no campo possui como uma característica o calendário escolar seguindo as temporadas de plantio e colheita, evitando assim a ausência dos estudantes na escola. Verificamos no PPP do colégio que o mesmo segue o calendário oficial (Governo do Estado), porém, quando há épocas de intenso trabalho na agricultura, o diretor informa que são feitos ajustes quanto a provas, trabalhos, atividades, mas sem alterar o calendário anual.

O espaço escolar não se limita à sala de aula, é muito mais rico. As aulas acontecem em sintonia com o meio ambiente, com os modos de vida do estudante e este se torna importante para o espaço escolar, o espaço feito para ele e para sua formação.

\section{ORGANIZAÇÃO POLÍTICA, MOVIMENTOS SOCIAIS E CIDADANIA}

Quando se fala em Educação do Campo, pensa-se em formar um cidadão que atuará no campo ou na cidade. Para isso o colégio deve possuir uma estrutura que mostre para o estudante sua importância para o meio em que vive. É importante que a escola possua uma gestão alinhada com seus objetivos, que pode ser mais democrática ou mais autoritária.

Quando perguntado sobre a organização política do colégio, os entrevistados falaram que as decisões são sempre feitas em grupo. O diretor cita o plano disciplinar, construído com os professores e discutido em assembleia com estudantes e pais, que em seguida é aprovado e colocado em vigor. Todo ano o plano disciplinar é revisto e atualizado. O PPP (2015) apresenta que 
A gestão da escola é traduzida como um ato político, porque implica sempre uma tomada de posição dos atores sociais. Assim sendo, sua construção não pode ser individual, mas coletiva, envolvendo os diversos atores na discussão e na tomada de decisões (PARANÁ, 2015, p. 34).

A fim de promover a organização dentro de sala de aula e preparar os estudantes para a sociedade, a sala de aula foi planejada (Figura 2), segundo o diretor, como um grupo de trabalho, onde a turma é dividida em equipes de quatro estudantes, onde um deles é o coordenador. Cada turma possui dois líderes, um menino e uma menina e dois professores, eleitos pela classe escolar. Os grupos e o coordenador mudam a cada trimestre. Na visão do diretor, isso contribui para a formação de lideranças, para se trabalhar no coletivo, um diferencial na formação desse estudante na luta por seus direitos de cidadão.

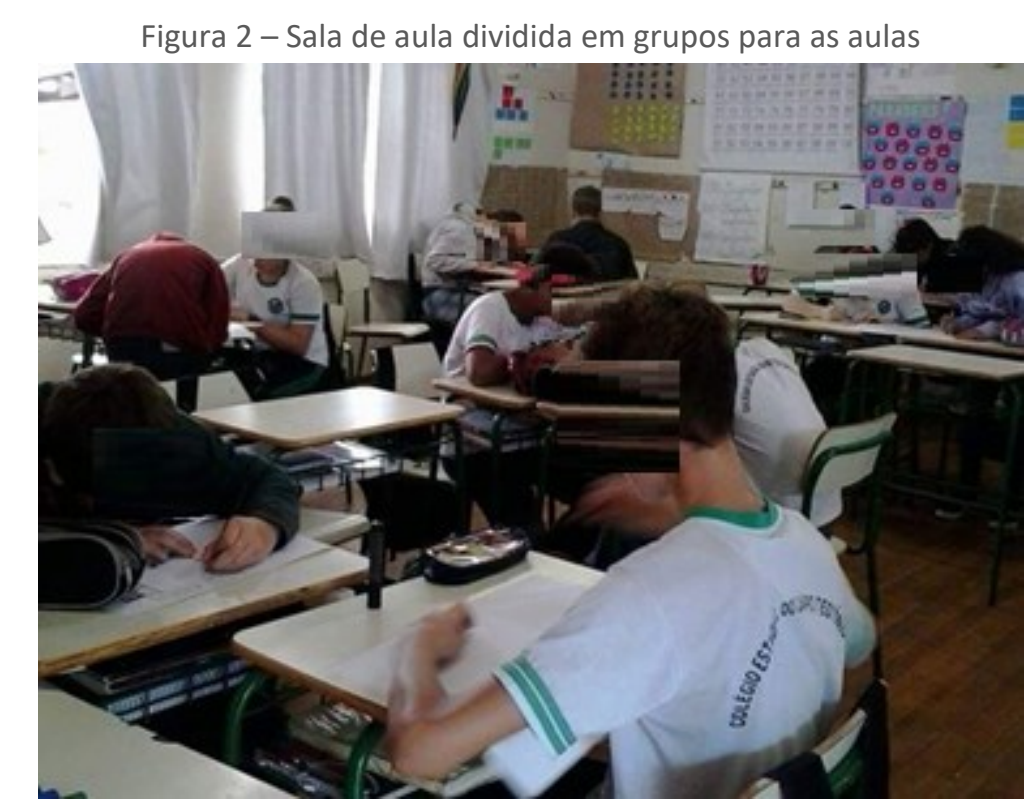

Fonte: coordenação do colégio (2015).

A participação dos estudantes é muito importante, porque é por eles e para eles que o colégio existe. Para o diretor é muito gratificante ver os estudantes saírem do colégio e ingressarem em grandes universidades, além de vários estudantes que vão para o colégio agrícola:

Todos os anos temos enviado três/quatro estudantes para o colégio agrícola em Foz (neste ano foram quatro), de onde tem saído grandes técnicos agrícolas. Um plano futuro é a criação de um pós-médio em agricultura familiar, tendo um espaço próprio para plantios, criação de animais, a fim de que no futuro o estudante aplique o conhecimento dele na comunidade e se torne um cidadão presente nela (ENTREVISTA A, SCHRENK, 2015).

Para os entrevistados, ver os estudantes saírem da sala de aula e permanecer no campo é um fato que motiva cada vez mais a lutar pelo campo. Porém, é perceptível uma dificuldade quanto ao apoio do governo na identificação como um colégio do campo. O diretor diz que muitas vezes são vistos como um colégio qualquer, não como um colégio do campo, mas a busca pelo reconhecimento nunca acaba. 


\section{COMUNIDADE}

O apoio da comunidade na qual o colégio está inserido é um aspecto bastante presente. Segundo as DCEC (2006), a participação dos pais e familiares e da comunidade em geral é fundamental para o funcionamento do colégio. É indispensável que o estudante perceba que ele é importante para a comunidade onde ele está inserido. O PPP (2015) do colégio tem por filosofia de trabalho educacional a formação do cidadão consciente, crítico e autônomo, envolvido com o próprio desenvolvimento e com o da comunidade. Ele enfatiza que a presença da família no espaço escolar pode ser entendida como um fator extremamente importante para o sucesso da aprendizagem do estudante.

Para que o estudante perceba sua importância para este local, ele deve conhecê-lo e, segundo o diretor, esse é um dos enfoques do programa "Mais Educação", a memória, a história da comunidade, onde se tem um professor morador da comunidade que, juntamente com os estudantes, fazem um estudo da comunidade, dos pioneiros, dos professores, entre outros, para que conheçam essa história, se sintam membros integrantes e participantes de todo esse processo. Para ilustrar essa preocupação, trazemos um recorte de jornal sobre o Resgate da Memória nas Escolas do Portão do Ocoy publicado no Jornal Mensageiro de Medianeira no ano de 2014, que mostra a preocupação do colégio em apresentar para os estudantes a história da escola onde estudam e o quanto ela foi importante para a formação da comunidade e das pessoas que ali moram.

Outro fator que exemplifica a forte relação do colégio com a comunidade é a festa junina. Juntamente com a festa junina é realizado o concurso da macarronada, onde, segundo a professora, é muito grande o empenho por parte de todos para o sucesso desse evento. Vários pais e outros membros da comunidade se disponibilizam para fazer porções de macarrão. $O$ diretor diz que cada turma tem a responsabilidade de fazer uma porção de macarrão, e os professores também se dividem em grupo para participar. Além disso, as apresentações das turmas são feitas no dia da festa para toda a comunidade. $O$ colégio e a comunidade em geral veem a festa como uma confraternização que aproxima as pessoas, que renova o comprometimento da sociedade com a escola, além de fazer com que o estudante se sinta importante para o colégio e para a comunidade onde vive.

\section{CONCEPÇÃO DOS PROFESSORES SOBRE A EDUCAÇÃO DO CAMPO}

Como percebemos, para que a Educação do Campo ocorra, é necessário que a escola possua professores habilitados, funcionários conhecedores da linguagem do estabelecimento de ensino no qual estão inseridos. No colégio em questão, vemos a presença desses quesitos nas entrevistas, quando o diretor nos diz que grande parte dos professores e outros funcionários são filhos de agricultores e/ou residem na comunidade. $O$ colégio também promove seminários e cursos sobre a Educação do Campo e como aplicar esses conhecimentos à realidade do colégio.

As DCEC (2006) ressaltam sobre a importância dos documentos possuírem informações que levem à ocorrência da Educação do Campo. Segundo o diretor, são realizados vários encontros pedagógicos onde os professores estudam as diretrizes da Educação do Campo, reelaboram suas propostas de trabalho e 
contribuem para a reestruturação do PPP do colégio, buscando a caracterização da linguagem, da característica do campo no colégio e no estudante, fazendo-o estudante se identificar com o local em que vive.

É muito importante que os professores tenham conhecimento sobre a Educação do Campo e, como afirmam Antunes-Rocha e Martins (2009), a sua formação e especialização deve ser contínua. As DCEC (2006) destacam a importância da pesquisa constante, encontrando alternativas metodológicas que levem a realidade vivida pelos estudantes para a sala de aula, pois, não que seja impossível ensinar, mas a dificuldade do professor com pouco conhecimento e convivência com a Educação do Campo tende a ser maior do que o professor que vive no campo e que o conhece e luta por ele.

\section{RELAÇÕES ENTRE A CULTURA ESCOLAR DO CAMPO E O ENSINO DA MATEMÁTICA}

Os entrevistados informaram que ainda não existe uma disciplina específica para Educação do Campo e que as atividades relacionadas à disciplina nessa área são realizadas nas disciplinas específicas e no programa Mais Educação, sempre em contraturno. De acordo com o diretor, "é possível perceber o professor de matemática trabalhando área, perímetro, usando o espaço escolar e o espaço da comunidade, buscando o que o estudante já conhece" (ENTREVISTA A, SCHRENK, 2015). A professora de matemática comentou sobre algumas atividades realizadas: "O trabalho com a horta no cálculo de área e perímetro, cálculo da altura da árvore com base na sombra" (ENTREVISTA C, SCHRENK, 2015). Estas atividades evidenciam a presença da Educação do Campo nas aulas de matemática.

Por outro lado, verificando os cadernos (Figura 3) percebemos que poucas atividades referenciam o campo ou algum desdobramento do que ocorre no projeto Mais Educação. A primeira imagem ilustra o cálculo da árvore com base na sua sombra.

Figura 3 - Atividade no caderno de um estudante do 9o Ano

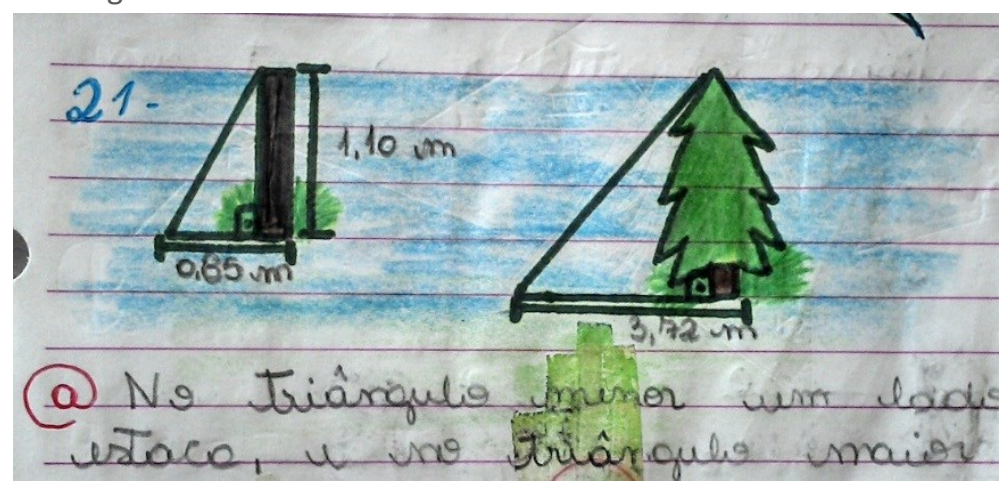

Fonte: caderno dos estudantes do ano anterior (2014).

Outra atividade que mostra relações com o campo apresenta o cálculo da área de determinada figura. Poderia ser feita utilizando qualquer figura, mas para esse cálculo a professora propôs utilizar uma folha de árvore (Figura 4). Foram analisados os cadernos do sexto, sétimo, oitavo e nonos anos do Ensino Fundamental do ano anterior à pesquisa e o que encontramos revela poucos elementos da Educação do Campo nos cadernos de matemática. 
Figura 4 - Atividade no caderno de um estudante do 8 ㅇ Ano

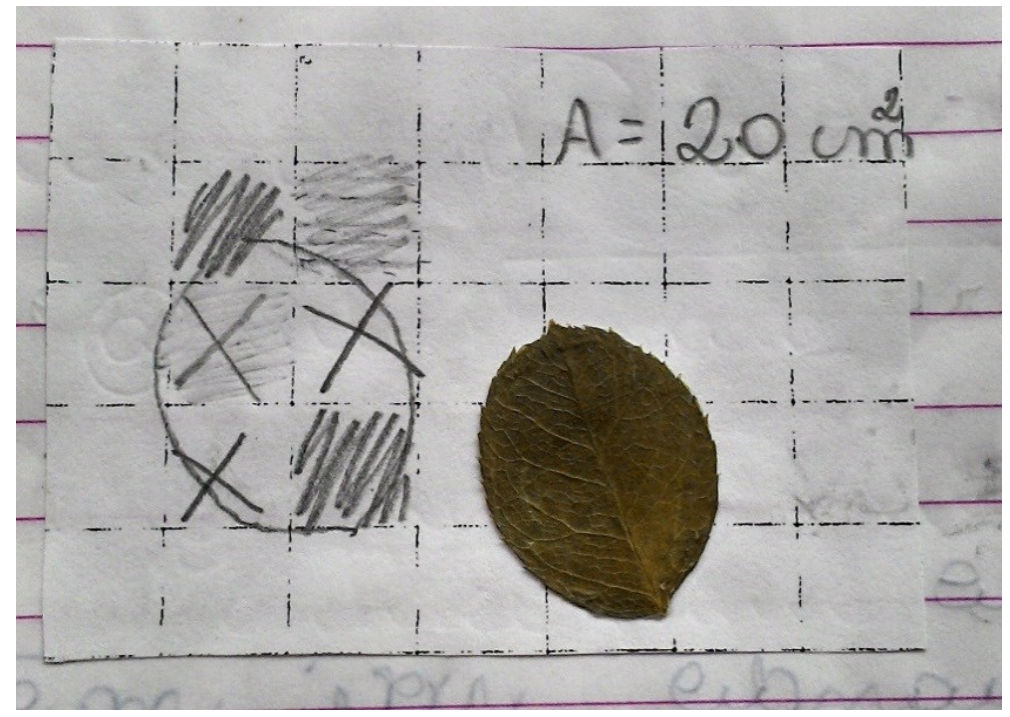

Fonte: caderno dos estudantes do ano anterior (2014).

A análise feita com os cadernos escolares foi crucial para entender o cotidiano escolar e um instrumento precioso para fazer o contraponto às entrevistas com a professora, o diretor e a pedagoga da escola.

Além dos cadernos, verificamos que alguns materiais criados pelos estudantes abarcavam duas ou mais disciplinas em um mesmo tema. $O$ diretor afirmou que vários trabalhos foram produzidos pelos estudantes, por exemplo, construção de maquetes da vila da comunidade, que envolveu aulas de artes, geografia e matemática e português. Para ele, na construção dessas maquetes foi possível verificar a colaboração da matemática, evidenciada no trabalho com a Geometria; da geografia, quando se trabalhou a localização da comunidade; e do Português, ao se abordar a nomenclatura das ruas.

A Figura 5 mostra um exemplo de como foi trabalhada a importância do cultivo da mata ciliar por meio do que os estudantes já conhecem no campo.

Figura 5 - Estudantes percebem na prática a importância da mata ciliar

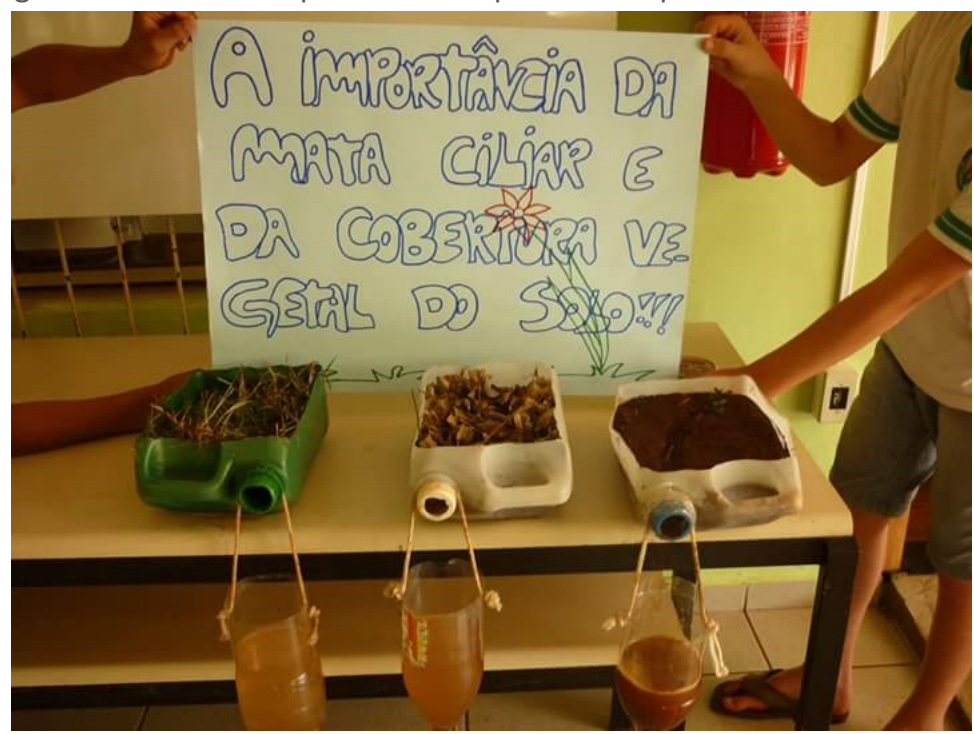

Fonte: coordenação do colégio (2015). 
A professora de matemática mencionou que o PTD (Plano de trabalho Docente) da disciplina de matemática segue o mesmo padrão das outras escolas, mas ela utilizou vários recursos além do livro didático, sempre buscando envolver a vivência dos estudantes.

O PPP (2015) apresentou a importância dos conteúdos das disciplinas escolares serem articulados com a realidade do campo valorizando o conhecimento trazido pelo educando, buscando somar a esse conhecimento os conteúdos escolares necessários. Ainda segundo o documento, a educação no campo deve ser pensada e desenvolvida para os sujeitos do campo, de forma a valorizar sua cultura e seus costumes. Para o diretor, é preciso usufruir do campo para auxiliar no aprendizado dos estudantes, trabalhando os conteúdos de modo que seja contemplada a realidade do estudante. Para entender que eles precisam do conhecimento matemático para dar conta de resolver os problemas que surgirão.

O trabalho com a horta, a construção de maquetes, cálculo de altura de árvores e outras partes do colégio são utilizadas, segundo os entrevistados, como estratégias de ensino que além de envolverem várias disciplinas em um mesmo tema, fizeram com que o estudante aprendesse tendo por base algo que ele já conhecia. O caráter prático das atividades pode fazer toda a diferença no aprendizado dos estudantes.

A professora de matemática evidenciou que apesar das atividades não estarem descritas no PTD, estas já constavam do planejamento de suas atividades no decorrer do ano, pois como ela lecionava no colégio há mais de 10 anos, o conhecia bem, assim como a vivência dos estudantes, o que lhe permitia perceber a importância do campo no ensino da matemática.

\section{CONSIDERAÇÕES FINAIS}

Por meio da análise das fontes e das entrevistas percebemos que há uma forte cultura escolar do campo explicitada no espaço escolar: horta, confecção de peças de artesanato, visita a outros colégios do campo, projetos sobre a história da escola, festa junina e grande envolvimento com a comunidade.

O projeto Mais Educação é um exemplo do resgate das raízes do campo naquela região para auxiliar no ensino dentro da escola e na vida dos estudantes. Percebemos nos trabalhos em grupo particularidades sobre a Educação do Campo, as quais foram possíveis de ver por meio das exposições realizadas pelos estudantes, nas participações em aulas práticas realizadas no colégio e fora dele, ou seja, na colaboração de cada um para o aprendizado de todos.

Na escola investigada a comunidade participa sempre das reuniões e decisões. Os eventos realizados pelo colégio contam sempre com uma grande colaboração por parte de toda a comunidade. Como grande parte dos professores pertencem à comunidade, estes sempre a mostram para quem vem visitá-la, a fim de que a respeitem como ela merece.

Com base nos documentos oficiais e na análise dos dados coletados, temos elementos suficientes para afirmar que a cultura escolar do campo está presente no colégio investigado, ou seja, identificou-se uma cultura escolar específica do campo. Os professores entrevistados demonstraram que possuem conhecimento 
da legislação vigente e que, respeitando as especificidades da escola, procuram pensá-la, na maioria das vezes, de acordo com o que está prescrito.

Os cadernos de matemática pouco mostram sobre a Educação do Campo, apesar da professora de matemática afirmar que busca fazer relações. O que fica mais evidente é na organização da escola e em atividades interdisciplinares (por exemplo a produção de maquetes).

Percebe-se, desta forma, que as aulas de matemática seguem, em grande medida, o padrão do planejamento e execução das outras escolas, com pouca especificidade da Educação do Campo.

Vale ressaltar que nos apropriamos de ferramentas da história cultural para contar esta história do presente e que os cadernos foram peças fundamentais para entender mais do cotidiano das aulas de matemática fazer o contraponto com as entrevistas e fontes oficiais da escola.

O currículo mostrou-se bastante urbanocêntrico, especificamente em relação as aulas de matemática, apesar de uma forte cultura escolar do campo estar presente na escola investigada.

Ao finalizar este trabalho nos perguntamos se em nossas escolas urbanas não estamos precisando, e muito, de características que estão na essência das escolas do campo: sentimento de pertencimento, envolvimento da comunidade, formação de lideranças, interdisciplinaridade, trabalho em grupo e valorização das práticas matemáticas locais. 


\title{
The countryside school culture and the teaching of mathematics
}

\begin{abstract}
With the objective of identifying the presence of the countryside school culture in the teaching of mathematics (final years of elementary school) in a school located in the rural area. The present research was based on the theoretical-methodological contribution of Cultural History through the concept of school culture (JULIA, 1990), having as sources: Elementary School (final years) students workbooks; teaching activities images; Political Pedagogical Project (PPP); math teacher planning; pertinent legislation; interviews with the school director, the mathematics teacher of the Elementary School, and the pedagogue. The curriculum was strongly urban-centered specifically in relation to mathematics classes, and although a strong school culture of the field is present in the school investigated, there is little presence of this field school culture specifically in the teaching of mathematics. As a final reflection, we ask ourselves if in our urban schools we do not need cultural elements school of the field: sense of belonging, community involvement, leadership formation, interdisciplinarity, team work and valorization of local mathematical practices.
\end{abstract}

KEYWORDS: Countryside Education. Mathematical Education. School Culture. 


\section{NOTAS}

1- Segundo as Diretrizes Curriculares da Educação do Campo (2006, p.9), “a Educação do Campo é uma política pública pensada, mediante a ação conjunta de governo e sociedade civil organizada. Caracterizada como o resgate de uma dívida histórica do Estado aos sujeitos do campo, que tiveram negado o direito a uma educação de qualidade, uma vez que os modelos pedagógicos ora marginalizavam os sujeitos do campo, ora vinculavam-se ao mundo urbano, ignorando a diversidade sociocultural do povo brasileiro, especialmente aquela expressa na prática social dos diversos sujeitos do campo".

2- O presente estudo, por envolver seres humanos foi submetido ao Comitê de Ética com o número do protocolo: 48885615.4.0000.5547 (aprovado em 17 set 2015).

3- Situado no Distrito Portão do Ocoí, Município de Missal, Estado do Paraná. As atividades de ensino deste estabelecimento iniciaram com as séries iniciais do Ensino Fundamental, mantida pela Prefeitura Municipal, em 1965 e recebia o nome de Escola Olavo Bilac. Em 1974 foi fundada como Grupo Escolar Municipal Olavo Bilac. Em 1982, a escola, foi autorizada a funcionar com as quatro séries finais do 1으 Grau sendo implantado gradativamente as demais, e em 1986 o curso de 1ㅇ Grau foi reconhecido pela Resolução № 1702/86 publicado no Diário Oficial de 14 de abril de 1.986, recebendo então a denominação Escola Municipal Olavo Bilac - Ensino de 1으. Grau. A partir do Reconhecimento do curso de 10 grau, foram municipalizadas as séries iniciais do Ensino Fundamental. Estas passaram a ser mantidas pela prefeitura, denominando-se assim Escola Municipal Olavo Bilac Educação Infantil e Ensino Fundamental. E as séries finais do Ensino Fundamental passaram a ser mantidas pelo Governo do Estado do Paraná denominando-se Escola Estadual Teotônio Vilella Ensino Fundamental.

4- Foram utilizados os cadernos do ano anterior a pesquisa para que o professor não fosse influenciado a fazer mais atividades relacionadas ao campo somente porque estava sendo realizada a pesquisa.

5- Conhecimento prévio é apresentado neste trabalho como o conhecimento que o estudante adquiriu fora da sala de aula, nesse caso, na sua vivência no campo.

6 - O Programa Mais Educação, instituído pela Portaria Interministerial no 17/2007 e regulamentado pelo Decreto 7.083/10, constitui-se como estratégia do Ministério da Educação para induzir a ampliação da jornada escolar e a organização curricular na perspectiva da Educação Integral. Neste programa os estudantes e professores realizam atividades extracurriculares, seja no trabalho com a horta, artesanato, entre outros, com o objetivo de ampliar a jornada escolar, contribuindo para a diversidade e riqueza de vivências.

\section{REFERÊNCIAS}

ALVES, G. L. (org.). Educação no Campo: Recortes no tempo e no espaço. Campinas, SP: Autores Associados, 2009. 305 p. (Coleção Educação Contemporânea).

ANTUNES-ROCHA, M. I.; MARTINS, A. A. (orgs.). Educação do Campo: Desafios para a formação de professores. Belo Horizonte: Autêntica Editora, 2009. 207p. (Coleção Caminhos da Educação do Campo).

BARBOSA, L. N. S. C. Entendimentos a respeito da matemática na educação do campo: questões sobre currículo. 2014. 234 f. Tese (Doutorado em Educação Matemática) - Instituto de Geociências e Ciências Exatas. Universidade Estadual Paulista "Júlio de Mesquita Filho". Rio Claro, SP, 2014. 
BRASIL. Conselho Nacional de Educação. Diretrizes Operacionais para a Educação Básica nas Escolas do Campo. 2002.

BRASIL. Secretaria de Educação Básica. Pacto Nacional pela Alfabetização na Idade Certa: Educação Matemática do Campo. Brasília, 2014.

CAVENAGHI, A. R. A.; BZUNECK, J. A. A motivação de alunos adolescentes enquanto desafio na formação do professor. In: CONGRESSO NACIONAL DE EDUCAÇÃO. 2009. p. 1478-1489.

D’AMBRÓSIO, U. Etnomatemática: elo entre as tradições e a modernidade. Belo Horizonte: Autêntica, 2005.

DENZIN, N. K.; LINCOLN, Y. S. Planejamento da pesquisa qualitativa: teorias e abordagens. Porto Alegre: Artmed, 2006.

DUARTE, R. Entrevistas em pesquisas qualitativas. Educar: Curitiba, n. 24, p. 213225, 2004.

GVIRTZ, S. Del currículum prescripto al currículum enseñado: uma mirada a lós cadernos de clase - 1.ed. Reimp. Buenos Aires: Aique Grupo Editor, 2009. 128p.

JULIA, D. A cultura escolar como objeto histórico. Revista Brasileira de História da Educação. Campinas, SP: SBHE, n.1, jan-jul, p.9-43, 2001.

KNIJNIK, G. Etnomatemática e politicidade da Educação Matemática. In: Primeiro Congressilvso Brasileiro de Etnomatemática. São Paulo: Universidade de São Paulo, 2000. p.17-20. Disponível em: <http://www2.fe.usp.br/ etnomat/siteantigo/anais/GelsaKnijnik.html>. Acesso em: 13 mai. 2017.

LÜDKE, M.; ANDRÉ, M. E. D. Pesquisa em educação: abordagens qualitativas. 9ạ reimpressão. São Paulo: Editora Pedagógica e Universitária, 2005.

MORAES, C. R.; VARELA, S. Motivação do aluno durante o processo de ensinoaprendizagem. Revista eletrónica de Educação, v. 1, n. 1, p. 1-15, 2007.

NAHIRNE, A. P.; STRIEDER, D. M. Metaestudo da Produção Científica sobre a Escola e a Educação do Campo. Educere et Educare, v. 12, n. 24, 2017. do Campo. Curitiba, 2006. 
PARANÁ. Colégio Estadual do Campo Teotônio Vilella. Projeto Político Pedagógico. 2015. 98 p.

SCHRENK, M. J. Educação do campo no ensino da matemática: um estudo do Colégio Estadual do Campo Teotônio Vilella. 2015. Trabalho de Conclusão de Curso. Universidade Tecnológica Federal do Paraná.

SCHRENK, M. J.; NOVAES, B. W. D. A Cultura Escolar do Campo e o Ensino de Matemática: aproximações e distanciamentos. In: Encontro Paranaense de Educação Matemática - EPREM, 2017, Cascavel - PR. Diversidade e Educação Matemática: desafios e perspectivas, 2017.

TRIVIÑOS, A. N. S. Introdução à pesquisa em ciências sociais: a pesquisa qualitativa em educação. São Paulo: Atlas, 1987. 175p.

VIDAL, D. G. Culturas escolares: estudo sobre práticas de leitura e escrita na escola pública primária (Brasil e França, final do século XIX). Campinas, SP: Autores Associados, 2005. (Coleção Memória da Educação). 187p.

WILLIANS, Raymond. O Campo e a Cidade na história e na literatura. Tradução Paulo Henrique Britto. São Paulo: Companhia das Letras, 2011.

Recebido: 22 fev. 2018

Aprovado: 23 jul. 2018

DOI: $10.3895 /$ actio.v3n3.7883

Como citar:

SCHRENK, M. J.; NOVAES, B. W. D. Relações entre a cultura escolar do campo e o ensino da matemática. ACTIO, Curitiba, v. 3, n. 3, p. 451-470, set./dez. 2018. Disponivel em: <https://periodicos.utfpr.edu.br/actio> Acesso em: XXX

Correspondência:

Maykon Jhonatan Schrenk

Esquina Eucalipto, s/n, Portão do Ocoí (zona rural), Missal, Paraná, Brasil.

Direito autoral: Este artigo está licenciado sob os termos da Licença Creative Commons-Atribuição 4.0

Internacional.

(c) (i) 